\title{
Feiras livres: campo fértil para a gestão da comunicação
}

Juliana Tourrucôo Alves

Especialista em Gestão da Comunicação pela Escola de Comunicações e Artes da Universidade de São Paulo (ECA-USP)

E-mail: jutourru@gmail.com

Resumo: Amparada a um estudo histórico sobre as feiras livres, a autora propõe um projeto de intervenção para o Sindicato do Comércio Varejista dos Feirantes do Estado de São Paulo. Nele, enumeram-se, entre outras ações, propostas para sistematizar o armazenamento e a recuperação de informações e dados institucionais sobre as feiras livres, os feirantes e a instituição. $O$ estudo contempla também orientações para a edição de livros e a promoção de exposições, palestras e treinamentos, tendo em vista a preparação dos atuais e novos feirantes para as novas projeções dos novos públicos da metrópole. Utilizou-se da metodologia qualitativa, baseada em estudos etnográficos.

Palavras-chaves: Feira livre, abastecimento, comércio, comunicação, sindicato.
Abstract: Backed with a historical study of the fairs, the author proposes an intervention projectfor the Union of Retail marketer of the State of São Paulo. The document lists, amongother things, proposals for the systematic storage and retrieval of information andinstitutional data on the fairs, the merchants and the institution. The study also includes guidelines for book publishing, and promotion of exhibitions, lectures and training in order to prepare the current and new stallholders to the new projections of the new public of the metropolis. We used qualitative methodology, based on ethnographic studies.

Keywords: Street market, supply, trade, communication, union.

Espaço informal por natureza, mas cada vez mais enquadradas em regras formais, as feiras livres existentes na cidade de São Paulo vivem um momento de transição. Enquanto alguns vislumbram seu fim, à vista da mudança de costumes da sociedade, outros acreditam que elas podem continuar a fazer parte da vida dos paulistanos, adaptando-se às novas realidades.

Apesar de as feiras livres terem seu funcionamento regulamentado por regras municipais, os feirantes fazem questão de reforçar e manter a aura de informalidade (não tributária, mas comportamental). Com seus processos comunicacionais submetidos a essa índole libertária - por vezes até anárquica -, a feira livre é um espaço arredio a intervenções externas isoladas. Assim, elaborar uma proposta de comunicação para o setor exige uma compreensão dessa natureza.

Sendo o Sindicato do Comércio Varejista dos Feirantes do Estado de São Paulo (Sincofer) um mediador desse universo informal com a sociedade formal 
comunicação \& educação • Ano XVI • número 2 • jul/dez 2011

e administrativamente constituída, optou-se por escolher a entidade como objeto de estudo e para experimento da implantação de um projeto de comunicação para o setor, prevendo a sua sobrevivência em meio às mudanças que cada vez mais se impõem ao cotidiano das aglomerações urbanas, em espaços públicos ou privados. Este artigo apresenta uma síntese da pesquisa apresentada junto ao Curso de Gestão da Comunicação, da Escola de Comunicações e Artes da Universidade de São Paulo, para a obtenção do título de especialista em Gestão da Comunicação.

Acrescento que não sou funcionária do sindicato e tampouco tenho qualquer vínculo pessoal com qualquer feirante. A escolha foi motivada pela abrangência do tema, que permite ricas abordagens nos campos do conhecimento, como: História, Geografia, Arquitetura, Economia e a Comunicação.

\section{A HISTÓRIA DAS FEIRAS LIVRES}

Enquanto o homem foi nômade, caçava-se e colhia-se o alimento para o consumo imediato. Entretanto, a criação de técnicas de plantio e de armazenamento, além de tecnologias como calendários e ferramentas para trabalhar

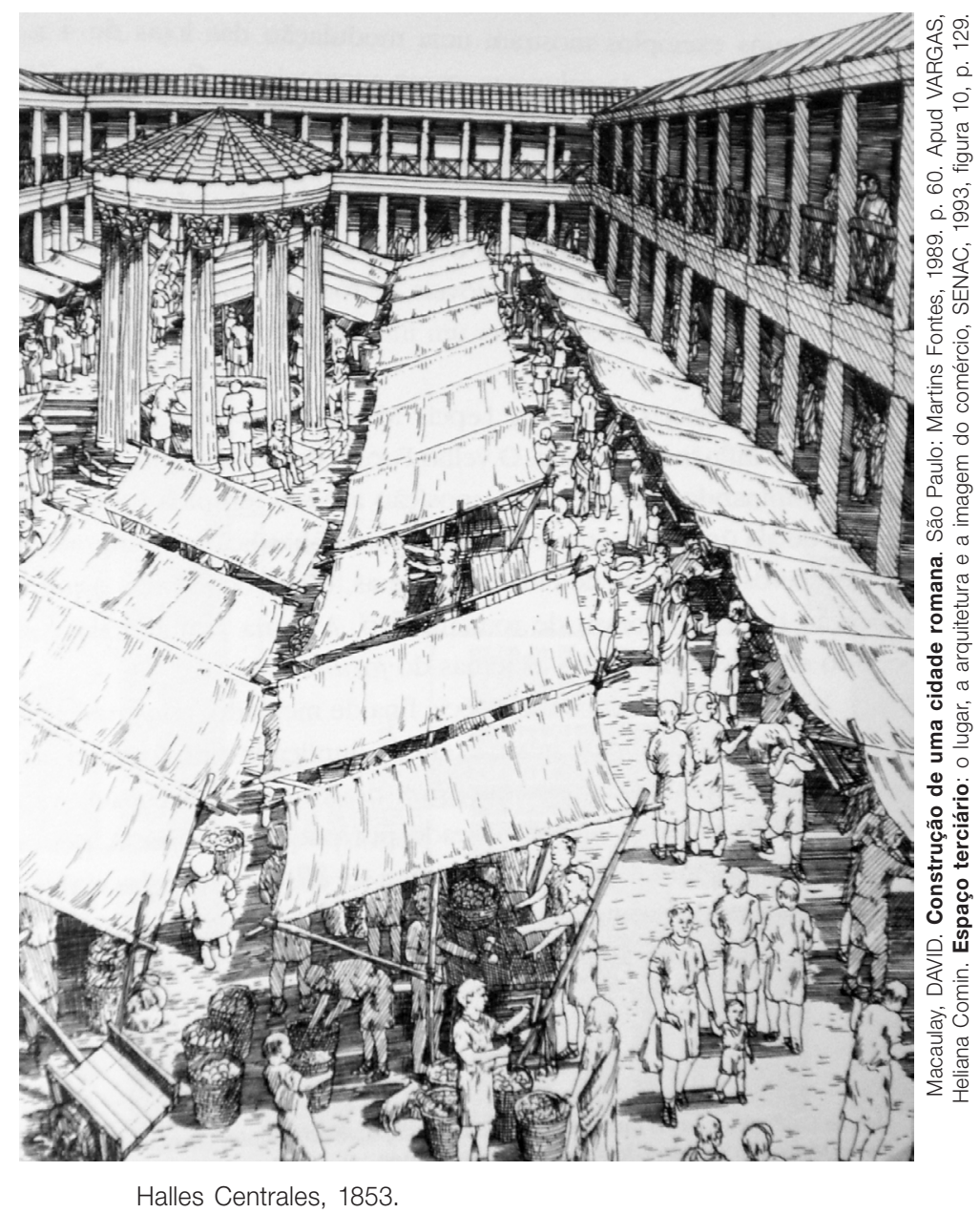


a terra, permitiu a uma boa parte desse grupo maior permanência junto a locais rurais e a vilarejos, onde existia aglomeração de barracas e tendas, com o objetivo de promover troca (e logo depois, a venda). Segundo Vargas, havia até um ideograma sumeriano que identificava essas áreas. "Um Y, talvez, indicasse que a ideia de mercado, como ponto de fusão e encontro de rotas de comércio".

Posteriores aos mercados, as feiras surgem na Idade Média como prática conjunta às festas religiosas, como documentam Rabelais e Bakhtin: "Era o caso, por exemplo, das 'festas do templo', habitualmente acompanhadas de feiras com seu rico cortejo de festejos públicos [...]"2.

Para Vargas, esses locais promoviam troca de ideias, informações e encontros sociais, e isso, provavelmente, foi o que levou vilarejos a se tornarem cidades ${ }^{3}$.

\section{AS FEIRAS LIVRES NA CAPITAL PAULISTA}

As feiras livres, segundo a Prefeitura Paulista, acontecem (informalmente) na cidade a partir de 1600. Cabe ressaltar que inúmeras informações históricas sobre elas foram captadas de forma fragmentada em livros e nas Atas da Câmara Municipal de São Paulo. As leituras desse documento permitiram, por exemplo, encontrar uma emblemática discussão sobre o tema em uma audiência, no dia 21 de março de 1914.

Alcântara Machado - Não os suprimo. As minhas palavras têm a máxima clareza. Em toda a parte, os mercados volantes funcionam contemporaneamente com os fechados.

Carlos Botelho - Esses mercados ao ar livre não são novidade nenhuma. Já existiam em São Paulo nos tempos coloniais. Eu conheci o mercados da rua da Quitanda nas calçadas daquela rua.

Alcântara Machado - [...] Mas são completamente diversos das quitandas a que o colega se refere. Nas quitandas do São Paulo antigo vendia-se em tabuleiros toda a sorte de mercadoria. Nos mercados volantes só se vendem certos e determinados artigos, e em lugares designados [...]

Carlos Botelho - A imundície, ainda que temporária, existirá da mesma forma nesses mercados.

Alcântara Machado - A experiência demonstra o contrário. Prouvera aos céus que tivéssemos a cidade de São Paulo tão limpa, tão asseada como Zurique ou Genebra!

Carlos Botelho - Era preciso que estivéssemos aparelhados como elas para fazer limpeza. Façam-se os mercados e verá o resultado: "já estamos sujos, e mais sujos ficaremos".

Alcântara Machado - São modos de ver... Entrego a ideia ao estudo do Sr. Prefeito municipal $(\ldots)^{4}$.

Seis meses e quatro dias depois após esse diálogo, no dia 25 de agosto de 1914, o prefeito Washington Luiz assinava o ato $710^{5}$, autorizando a criação dos mercados francos (as feiras livres).
1. VARGAS, Heliana Comin. Comércio: localização estratégica ou estratégia na localização? Tese de doutorado da Faculdade de Arquitetura e Urbanismo da Universidade de São Paulo (FAU/ USP). São Paulo, 1993. p. 132.

2. BAKHTIN, Mikhail. A cultura popular na Idade Média e no Renascimento: o Contexto de François Rabelais. Editora da Universidade de Brasília. Brasília, 1999. p. 4.

3. VARGAS, Heliana Comin. Espaço terciário: - lugar, a arquitetura e a imagem do comércio. São Paulo: SENAC, 2001. p. 96.

4. ATAS da Câmara da Vila de São Paulo, VII: 345. Apud BRUNO, Ernani da Silva. História e tradições da cidade de São Paulo. Rio de Janeiro: José Olympio, 1953.

5. RELATÓRIO da ata de 1914 da Câmara Municipal de São Paulo, p. 16. 
comunicação \& educação • Ano XVI • número 2 • jul/dez 2011

\section{AS FEIRAS PAULISTANAS NA CONTEMPORANEIDADE}

Desse ponto inicial e oficial, a implantação das feiras livres na capital paulista passou por muitas fases. Durante anos, elas foram bem-aceitas e reconhecidas como principal canal de abastecimentos de produtos hortifrutigranjeiros. Sua sobrevivência começa a ser ameaçada a partir da década de 1970. Mascarenhas e Dolzani apontam o surgimento do carro como um dos principais elementos de conflito com as feiras, entendidas como obstáculos ao fluxo e circulação dos automóveis.

Vargas e Sato acrescentam as mudanças nas atividades comerciais varejistas, como o surgimento dos primeiros supermercados ${ }^{6}$, presentes a partir de 1950. Seu início, aliás, foi desastroso. Foi preciso prever recepcionista para orientar o cliente a pegar o carrinho, escolher os produtos e se dirigir aos caixas ${ }^{7}$. Mas os empresários acertariam em cheio ao oferecer as vendas com sistema de crédito financeiro (cartões de crédito e de débito), a partir de 1980, e logo depois a compra on-line. Itens não contemplados em boa parte das feiras, o que para muitos consumidores é fator determinante na sua decisão de compra.

\section{O SINDICATO DO COMÉRCIO VAREJISTA DOS FEIRANTES DO ESTADO DE SÃO PAULO}

Localizado em um antigo edifício na Avenida Senador Queirós, centro de São Paulo, a instituição tem como logotipo - impresso em todas as cartas, ofícios, comunicados - a imagem mitológica do deus Mercúrio, que representa o diálogo, a informação e a comunicação. Comumente, esse signo representa os comerciantes. Daí os sindicatos ligados ao comércio, criados nos anos de 1940, fazerem uso dele. O órgão possui (2010) uma estrutura mínima, constituída por 13 integrantes, entre diretoria, eleita a cada cinco anos, além de colaboradores administrativos.

O Sincofer não possui uma comunicação planejada de forma a atuar como ferramenta

6. Os supermercados teriam sido criados nos Estados Unidos pelo empresário King Kullen, em 1930.

7. SATO, Leny. Processos cotidianos de organização do trabalho na feira livre. Tese apresentada ao Instituto de Psicologia da Universidade de São Paulo (USP). São Paulo, 2006. p. 44.

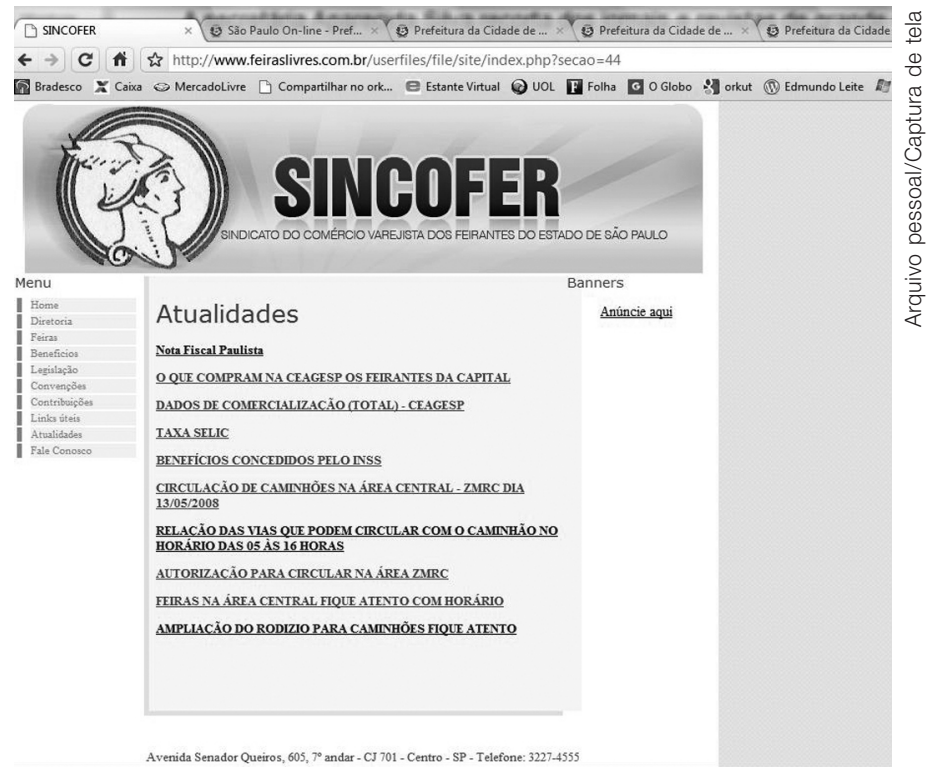

Site do Sincofer até a sua desativação, em setembro de 2010. 
das ocorrências); mural (recorte de notícias e reportagens da grande imprensa sobre o tema feiras); e o site (criado em 2006 e descontinuado em meados de setembro/2010).

\section{O PAPEL DO PESQUISADOR GESTOR}

Os pensamentos humanista, positivista e iluminista deixaram no DNA de boa parte da sociedade conceitos que refletiam apenas no sujeito do homem em si e na razão. Segundo Baccega, é necessário avaliar criticamente, no entanto, o papel e a função do emissor - sujeito que faz parte de uma classe social, uma nação e de tantos outros territórios de pertencimento ${ }^{8}$.

Sua mensagem, portanto, será marcada por esses traços. Do outro lado, o que recebe (o receptor) é também um cidadão com características sociais próprias, cuja interpretação vai corresponder àquela que faça sentido em seu universo ${ }^{9}$.

Os recursos que o emissor e o receptor têm para se expressar incidem na comunicação visual, tátil, corporal, auditiva e verbal. Essa última usa como recurso a palavra. "Signo neutro, que penetra nas relações sociais, incorporando a carga valorativa conforme seu uso" ${ }^{10}$.

Além de ter em mente esse conceito, o gestor deve primar ao longo de seu projeto por se dedicar a aprender, a avaliar e a compreender as situações que acontecem no cotidiano, espaço da espontaneidade e de surpresa ${ }^{11}$.

As feiras livres estão presentes no cotidiano. Elas surgem como um lugar de diálogo, ao contrário do hipermercado, "um não lugar onde se 'conversa' com placas e com máquinas"12.

Outro fator determinante para legitimar o trabalho de um gestor na temática das feiras livres é que ele possibilita um estudo das ciências sociais. Diz Ianni que as ciências sociais estão sendo desafiadas a pensarem a globalização do mundo. Ele define a sociologia como a ciência dos sistemas sociais, e a globologia como a ciência do sistema global. Segundo ele, a globalização intensifica as relações sociais em escala mundial, o que permite a ligação de localidades distantes, de tal maneira que acontecimentos locais são modelados por eventos ocorrendo a muitas milhas de distância e vice-versa. A feira livre é parte de um fenômeno sociocultural e abrange um campo fascinante de investigação etnográfica global por muitos anos ${ }^{13}$.

\section{METODOLOGIA DE PESQUISA}

Na fase de definição ou construção do objeto de pesquisa, as operações iniciais de elucidação conceitual do problema e de sua contextualização constituem as fontes básicas das hipóteses de pesquisas. Desse ponto de vista, as hipóteses têm sua origem na problemática teórica, o que se constitui em hipóteses de trabalho. Neste projeto, que faz uso de uma metodologia qualitativa, baseada em estudos etnográficos, foram abordadas, com ênfase, hipóteses de
8. BACCEGA, Maria Aparecida. A práxis do campo da comunicação e o profissional gestor de processos comunicacionais: conhecimento, sensibilidade e técnica como base para a intervenção na realidade. In: COSTA, Maria Cristina Castilho (Org.). Gestão da comunicação: projetos de intervenção. São Paulo: Paulinas, 2009.

9. Ibid., p. 11.

10. Ibid., p. 13.

11. Ibid., p. 19.

12. Ibid., p. 20.

13. IANNI, Octavio. Globalização: novo paradigma das ciências sociais. Instituto dos Estudos Avançados da Universidade de São Paulo (IEA-USP). São Paulo, 1994. p. 151-152. 
pesquisas sobre as rupturas comunicacionais existentes na instituição foco e que abordam as feiras livres como um todo.

Uma das hipóteses é que a gestão do Sindicato do Comércio Varejista dos Feirantes do Estado de São Paulo não oferece ferramentas ou pesquisas de campo eficazes para promover a aproximação do feirante com sua nova clientela. Sendo assim, como já indicado por Vargas, durante entrevistas para a autora, nas feiras de bairros nobres (ou de alto poder aquisitivo) prevalece o público de idosos e de empregadas domésticas.

Se o sindicato não planejar essa projeção de público, as feiras não vão ter uma conectividade com a nova geração de consumidores, que aflora nesta sociedade dinâmica, fragmentada e mutante deste terceiro milênio.

Outra hipótese é a falta de preparação de novos feirantes para assumir a postura de comerciantes aptos a operar a logística de um comércio de rua, que preza pelo atendimento personalizado e pelas relações de confiança. Ele também precisa receber capacitação para lidar com as pendências burocráticas de administrar um pequeno negócio. Essa constatação ganha amparo nas declarações de Peliciolli, antiga secretária do Sindicato dos Feirantes, que, durante entrevista concedida para esta pesquisa, fez a seguinte análise:

Hoje, a feira está caminhando para uma coisa que também não é muito boa: ela está vendendo muita quinquilharia. Porque a feira livre hoje é um dos poucos lugares onde se dá emprego para pessoas que não são habilitadas em nada. Coisa que no passado o feirante era um comerciante. Comerciante gabaritado, que tinha conhecimento, que assumia sua barraca como uma firma. Fazia imposto de renda, pagava seus empregados, registrados. Essas bancas grandes estão desaparecendo. Porque a Prefeitura não dá mais licença para essas bancas e porque os parentes mais próximos, filhos e irmãos, não estão mais interessados em trabalhar na feira. Os filhos dos feirantes estudaram, querem outra vida. Porque a vida de um feirante é realmente muito puxada, muito difícil, nos dias de hoje. Por que antes valia a pena? Porque eles vendiam muito e ganhavam muito. Hoje, o sacrifício é muito grande para um capital pequeno $(. . .)^{14}$.

A falta desse serviço, que poderia ser apoiada pelo Sindicato, é desenvolvida de forma pulverizada para trabalhadores de rua, pelo Serviço Brasileiro de Apoio às Micro e Pequena Empresas (SEBRAE). O desafio é saber como implantar um plano de comunicação para uma categoria que, segundo o presidente do Sindicato, não está disposta a mudar sua forma de diálogo. "Feirante é sabe-tudo", como disse José Gonçalves Torres, presidente do Sincofer.

A terceira hipótese incide sobre a atuação do poder municipal da capital em administrar as feiras livres de forma racionalizada, sistema similar ao adotado pelos supermercados. O secretário de Abastecimento, como afirmou na entrevista, vem estruturando as feiras tendo em mente a logística desse tipo de comércio. Ocorre que as feiras têm uma origem totalmente destoante dessa premissa. Como definiu Vargas, durante as entrevistas para a autora, as feiras têm origem e influência dos mercados árabes e os shoppings e supermercados usam referências da cultura anglo-saxônica.

14. Extraída da entrevista de Fátima Pellicioli. 
Dois são os objetivos gerais do projeto:

1. Analisar ações junto ao Sindicato para aumentar o número de consumidores nas feiras livres, tendo como prioridade o público jovem.

2. Formatar junto ao Sindicato formas de capacitar o novo feirante para os novos modos de comunicação, intermediados por novas mídias e até por sistemas virtuais de pagamento.

Mais especificamente, o projeto de intervenção pretende:

1. Conhecer o Sindicato do Comércio Varejista dos Feirantes do Estado de São Paulo em sua história e trabalho em defesa dos feirantes.

2. Resgatar a história das feiras livres (mercados francos e mercados livres, denominações já usadas pela Prefeitura paulista para esse tipo de comércio).

3. Conhecer a opinião de profissionais sobre as feiras livres.

4. Pesquisar a opinião de especialistas sobre o sindicato e as feiras livres.

Outra informação valiosa na construção desse cenário surgiu das análises simplificadas de dados publicados nos estudo da pesquisadora Olmária Guimarães ${ }^{15}$ e nos números fornecidos pela Secretaria de Abastecimento (2010).

Ao correlacionar essas informações ao crescimento populacional de São Paulo, segundo o Instituto Brasileiro de Geografia e Estatística (IBGE), teremos a seguinte síntese:

\begin{tabular}{|l|l|l|l|l|}
\hline Ano & $1964 / 1965^{16}$ & $2009 / 2010$ & $\%$ crescimento & Números \\
\hline População* & 5 milhões & 11 milhões & $120 \%$ & +6 milhões \\
\hline Feiras** & 452 & 903 & $99,8 \%$ & +451 \\
\hline Feirantes $^{\star \star}$ & 12.675 & 10.350 & $-18,34 \%$ & -2325 \\
\hline
\end{tabular}

* Estimativas do Instituto Brasileiro de Geografia e Estatística 2000.

** Dados informados pela secretaria de Abastecimento da cidade de São Paulo para Olmária Guimarães e para a atual pesquisadora em 2009/2010.

É possível observar nesse período um crescimento populacional da cidade de São Paulo e um aumento do número de feiras. Porém, há uma redução no número de feirante. Essa informação pode ser interpretada como um indício de que as feiras estão silenciosamente passando por uma alteração em sua forma.

Os instrumentos de pesquisa utilizados foram:

a) pesquisa bibliográfica do curso de gestão;

b) pesquisa documental, no Arquivo Público do Estado de São Paulo e Arquivo Histórico Municipal Washington Luís, da cidade de São Paulo; pesquisa nos arquivos das bibliotecas da Universidade de São Paulo e do jornal O Estado de S. Paulo; consultas ao site da Prefeitura de São Paulo e entrevistas, realizadas com estrutura aberta, sem um padrão de perguntas a ser seguido pelo entrevistador ou qualquer imposição aos entrevistados para que respondessem as questões colocadas. Foram entrevistados: Maria de Fátima Almeida Pellicioli (1943) - entre 24 de maio de 1961 e final de 2008, ela foi secretária da diretoria do Sincofer; José Gonçalves Torres (1954), presidente do Sincofer; José Roberto Graziano (1951), supervisor-geral de Abastecimento da cidade de

15. GUIMARÃES, Olmária. O papel das feiras livres no abastecimento da cidade de São Paulo. Dissertação de mestrado não publicada, Instituto de Geografia, Universidade de São Paulo. São Paulo, 1969.

16. Ibid. 
comunicação \& educação • Ano XVI • número 2 • jul/dez 2011

São Paulo, desde 2005; Dra. Heliana Comin Vargas (1951), professora titular da Faculdade de Arquitetura e Urbanismo da Universidade de São Paulo (FAU/ USP) e autora de vários livros sobre comércio terciário; Ronaldo Alberto Faria da Silva (1955), conhecido como Carioca, feirante há 30 anos, sendo 20 deles na Oscar Freire, aos domingos.

\section{O PROJETO DE INTERVENÇÃO}

Este projeto de intervenção parte da premissa de que a sistematização de armazenamento e recuperação de informações e dados é o primeiro passo para estruturar um discurso institucional, além de possibilitar a constituição efetiva de uma memória comum.

Por meio do controle da memória coletiva, a história do presente se estabelece como um poderoso elemento de composição da cultura histórica e se firma como uma vertente ideológica que atua sobre o acontecer e, por essa via, interfere no processo histórico ${ }^{17}$.

Além disso, é importante esclarecer que as ações de comunicação (interna e externa) propostas visam, em primeira instância, ao aprimoramento e à intensificação das relações que já estão estabelecidas no ambiente do Sindicato, amparadas na análise das entrevistas realizadas e fontes consultadas nesta pesquisa.

\section{Comunicação interna}

1. Criação de uma base de dados para que os fluxos de comunicação que se entrecruzam no Sindicato sejam devidamente tratados e conduzidos a favor da gestão institucional. Atrelada a essa ação, o Sindicato deve também prever a capacitação técnica da equipe que vai operar o sistema.

2. Reestruturação do site do Sindicato. O site do Sindicato é pouco atraente e funcional. Outros sindicatos se valem de uma parceria com a Fecomércio para oferecer um site mais dinâmico e informativo e até lucrativo, graças à comercialização de anúncios.

\section{Comunicação externa}

Prevê ações junto ao poder público, à sociedade e à classe dos feirantes.

1. Parceria com o Museu da Pessoa, e da Imagem e do Som, para prever a

17. MOTTER, Maria Lourdes. Ficção e história: imprensa e construção da realidade. São Paulo: Villipress/Arte e Ciência, 2001. p. 35. captação e documentação da história e da memória do feirante em São Paulo, bem como apresentar esse conteúdo em exposições.

2. Parceria com instituição reconhecida no segmento de empreendedorismo, gestão de negócios, apoio à pequena e média empresa, como o SEBRAE.

3. Ao formatar o banco de dados e um sistema de métricas sobre as feiras livres e os feirantes, o Sindicato seria o polo gerador de informações oficiais 
para os pesquisadores e, em contrapartida, teria acesso às análises e avaliações realizadas por cientistas.

4. O Sindicato pode fazer parcerias com editoras focadas em áreas de abastecimento para viabilizar a publicação de um jornal (ou boletim informativo).

5. Para a comemoração do centenário das feiras livres em São Paulo, a ser completado em 25 de agosto de 2014, pode-se prever palestras, workshops $e$ encontros com dirigentes do Patrimônio Histórico. Pode-se também planejar $o$ primeiro livro dedicado a falar sobre as feiras livres em São Paulo.

\section{CONSIDERAÇÕES FINAIS}

Poucos dias antes da entrega do trabalho de conclusão para o Curso Gestão da Comunicação, os feirantes e a feira livre voltaram às telas de tevê, à casa de milhões de brasileiros que à noite assistem à novela. Passione ${ }^{18}$, de Sílvio de Abreu, trouxe Vera Holtz como a feirante Maria Candelária Lobato, a Candê. Mulher de personalidade extrovertida, expansiva, forte e honesta junto à comunidade do bairro do Tatuapé, zona leste de São Paulo.

Essa personagem, somada a outras aparições emblemáticas de feirantes na telenovela, nessa mesma emissora, como a Dona Хера (na obra homônima), inter-

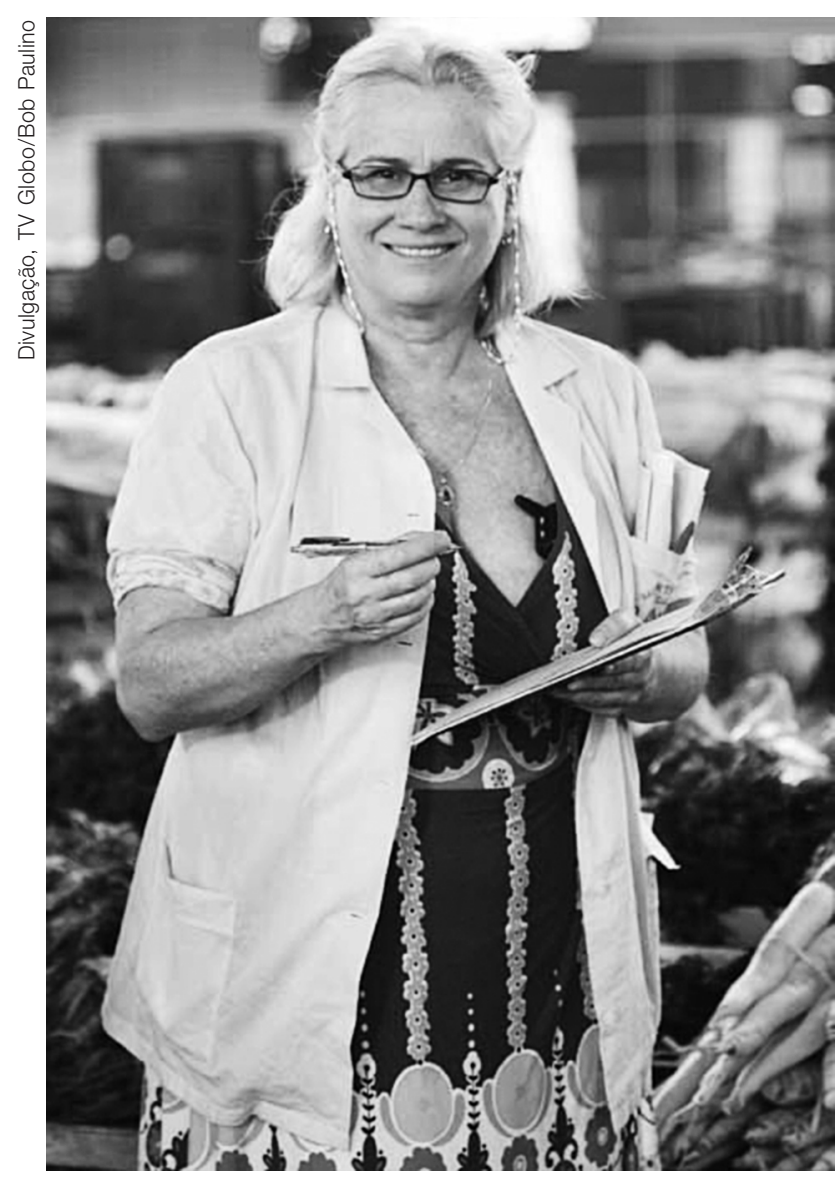

A feirante Candê (Vera Holtz) na telenovela Passione. pretada por Yara Côrtes, em 1977, ou o Juca, Tony Ramos, em A Próxima Vítima, em 1995. $\mathrm{Ou}$, ainda, as aventuras do feirante Vitório Testada, vivido por Otelo Zeloni, que após ganhar na lotéria vira $O$ Conde Zebra, nome da trama exibida em 1973 na TV Tupi. Notável é perceber que esses enredos certamente sensibilizaram o telespectador, estabelecendo uma relação de simpatia e até mesmo identidade. A mídia, em contrapartida, poderá abrir mais espaço em suas programações para serem ocupadas por esses personagens reais, que enfrentam dramas pessoais, sociais, culturais, políticos, preconceitos, entre tantos outros desafios.

Apesar da perseverança pessoal e otimismo, não é possivel afirmar se o projeto

18. PASSIONE. De Silvio de Abreu, direção de Denise Saraceni. Brasil: Rede Globo. 209, cap. 17, maio 2010 a 14 jan. 2011. 
comunicação \& educação • Ano XVI • número 2 • jul/dez 2011

de intervenção será implementado pelo Sindicato. Dependerá de vontade, de circunstâncias políticas, materiais e comportamentais. Por ora, a avaliação - de todo esse apanhado histórico e dessas propostas de intervenção - junto à academia já parametrizará a recepção, a pertinência e a viabilidade dessas ideias.

\section{REFERÊNCIAS BIBLIOGRÁFICAS}

Atas da Câmara da Vila de São Paulo, VII: 345. Apud BRUNO, Ernani da Silva. História e tradições da cidade de São Paulo. Rio de Janeiro: Editora Livraria José Olympio, 1953.

BACCEGA, Maria Aparecida. A práxis do campo da comunicação e o profissional gestor de processos comunicacionais: conhecimento, sensibilidade e técnica como base para a intervenção na realidade. In: COSTA, Maria Cristina Castilho (Org.). Gestão da comunicação: projetos de intervenção. São Paulo: Paulinas, 2009.

BAKHTIN, Mikhail. A cultura popular na Idade Média e no Renascimento: o contexto de François Rabelais. Brasília: Editora da Universidade de Brasília, 1999.

GUIMARÃES, Olmária. O papel das feiras livres no abastecimento da cidade de São Paulo. Dissertação de mestrado não publicada, Instituto de Geografia, Universidade de São Paulo, São Paulo, 1969.

IANNI, Octavio. Globalização: novo paradigma das ciências sociais. Instituto dos Estudos Avançados da Universidade de São Paulo (IEA-USP), São Paulo, 1994.

MOTTER, Maria Lourdes. Ficção e história: imprensa e construção da realidade. São Paulo: Villipress/Arte e Ciência, 2001.

RELATÓRIO da ata de 1914 da Câmara Municipal de São Paulo.

SATO, Leny. Processos cotidianos de organização do trabalho na feira livre. Tese apresentada ao Instituto de Psicologia da Universidade de São Paulo (USP), São Paulo, 2006.

VARGAS, Heliana Comin. Espaço terciário: o lugar, a arquitetura e a imagem do comércio. São Paulo: SENAC, 2001.

Comércio: localização estratégica ou estratégia na localização? Tese de doutorado da Faculdade de Arquitetura e Urbanismo da Universidade de São Paulo (FAU/USP), São Paulo, 1993.

\section{ENDEREÇOS ELETRÔNICOS}

$<$ www.feiraslivres.com.br $>$ (fora do ar)

$<$ www.portal.prefeitura.sp.gov.br/secretarias/abastecimento>

$<$ www.ibge.gov.br/home/>

$<$ www.teledramaturgia.com.br/> 